\title{
Hydrogen Permeability of Polymer Matrix Composites at Cryogenic Temperatures
}

\author{
Ray W. Grenoble*, Thomas S. Gates ${ }^{\dagger}$, \\ NASA Langley Research Center \\ Hampton, VA 23681
}

\begin{abstract}
This paper presents experimental methods and results of an ongoing study of the correlation between damage state and hydrogen gas permeability of laminated composite materials under mechanical strains and thermal loads. A specimen made from IM-7/977-2 composite material has been mechanically cycled at room temperature to induce microcrack damage. Crack density and tensile modulus were observed as functions of number of cycles. Damage development was found to occur most quickly in the off-axis plies near the outside of the laminate. Permeability measurements were made after 170,000 cycles and 430,000 cycles. Leak rate was found to depend on applied mechanical strain, crack density, and test temperature.
\end{abstract}

\section{Introduction}

$\mathrm{F}$ uture space transportation vehicles will put a premium on the design of lightweight structures and materials to meet the increased demands on performance. For spacecraft fueled by cryogenic fluids, one area identified as a potential source for significant weight reduction is the replacement of traditional metallic cryogenic fuel tanks with advanced polymeric matrix composite (PMC) tanks. The interest in design of cryogenic-fuel tanks for spacecraft using polymeric composite materials goes back several years to the research associated with the National Aerospace Plane (NASP) and the single-stage-to-orbit (SSTO) vehicles ${ }^{1}$. For these vehicles, PMC tank concepts were proposed for both the liquid-oxygen tanks and the liquid-hydrogen tanks. These studies addressed weight and cost benefits as well as the complex technical issues such as fatigue crack resistance and oxidation-corrosion resistance. As these studies matured, it was recognized that permeation resistance of the tanks could be the overriding design criteria because of the implications that damage initiation and growth and the resulting permeation (or leak) would have on both durability and safety of the vehicle.

The occurrence of damage and degradation in polymeric composites at cryogenic temperatures has been looked at in several recent studies. Bechel et.al. ${ }^{2}$ have shown that thermo-cycles (cryogenic to elevated temperature) will induce matrix cracks in a relatively low number of cycles. Gates et.al. ${ }^{3}$ also measured degradation of mechanical properties in PMC's as a function of aging at cryogenic temperatures. $\mathrm{Roy}^{4}, \mathrm{Noh}^{5}$ have investigated the relationship between mechanical loading and microcrack initiation and delamination growth. Relationships between permeability and crack density and crack opening displacement have been explored in these recent studies. In related studies, standard experimental procedures and methods for measuring hydrogen gas permeation (or leak), through composite materials, at cryogenic temperatures, have been under development to support the use of reusable composite cryotanks. Most notable of the published studies include the work performed by Yokozeki et al. ${ }^{6}$ and Rivers et al. ${ }^{7}$. The tests by Yokozeki et al. were performed using helium gas on composite tubular specimens mechanically loaded while at cryogenic temperatures. This study also measured crack density as a function of the load history. The tests by Rivers et al. were performed on sandwich composite panels mechanically loaded in bending using both liquid helium and liquid hydrogen. It is useful to note that both of these

\footnotetext{
* Graduate Student Co-op, Mechanics of Structures and Materials Branch

${ }^{\dagger}$ Senior Materials Research Engineer, Mechanics of Structures and Materials Branch, Associate Fellow AIAA 
studies concluded that the leak rate was unaffected by test temperature. Additional studies related to modeling gas permeability in composite laminates can be found in Ref. [8].

The objective of the current study is to experimentally study the relationship between thermal-mechanical induced damage and hydrogen gas permeation in laminated graphite/epoxy composite materials. The preliminary studies by the authors. ${ }^{911}$ have been extended through systematic measurements of permeation in damaged laminates using damage state, static load, and specimen temperature as test variables. The test methods will be outlined and results will be presented that illustrate the relationships between the test variables and permeation.

\section{Materials}

All composite test specimens were fabricated from IM-7/977-2, an intermediate modulus carbon fiber reinforced toughened epoxy. Flat panels were fabricated by hand layup, followed by vacuum bag / autoclave processing. The panels were cured at $177^{\circ} \mathrm{C}$. Ultrasonic NDE of the resulting panels revealed no significant internal anomalies. All fabrication work was performed by Northrop Grumman Corporation. All specimen preparation and testing was performed at NASA Langley Research Center. The specimen ends were tabbed with $1.91 \mathrm{~cm}$. thick G10 composite laminate. The specimens' free edges were polished prior to test to facilitate examination and quantification of edge crack density.

The laminate used in this study was $\left[+45 / 90_{3} /-45 / 0_{3} /-\right.$ $\left.45 / 90_{3} /+45\right]$, approx $0.17 \mathrm{~cm}$. in thickness. The test panels in this study are approximately 5 -inches wide by 24 -inches long. Lamina and laminate properties as a function of temperature were measured in previous studies ${ }^{11}$ and are presented in Table 1.

Table 1. Tensile Properties of IM-7/977-2 Composite

\begin{tabular}{|c|c|c|}
\hline \multirow{2}{*}{$\begin{array}{l}\text { Property } \\
\text { (Tensile) }\end{array}$} & \multicolumn{2}{|c|}{ Test Temperature } \\
\hline & $-196^{\circ} \mathrm{C}$ & $23^{\circ} \mathrm{C}$ \\
\hline $\mathrm{E}_{11}$ (Msi) & 23.0 & 26.13 \\
\hline $\mathrm{E}_{22}(\mathrm{Msi})$ & 1.71 & 1.20 \\
\hline $\mathrm{G}_{12}(\mathrm{Msi})$ & 1.13 & 0.90 \\
\hline$\sigma_{11}(\mathrm{ksi})$ & 157.3 & 317.5 \\
\hline$\sigma_{22}(\mathrm{ksi})$ & 16.23 & 11.20 \\
\hline $\mathrm{E}_{\mathrm{xx}}(\mathrm{Msi})^{* *}$ & 7.62 & 7.91 \\
\hline$\sigma_{\mathrm{x}}(\mathrm{ksi}) * *$ & 2.12 & 6.83 \\
\hline
\end{tabular}

\section{Experimental Methods}

The test sequence started with an as-fabricated, undamaged specimen. In order to create leak paths within the specimen, microcrack damage was induced through cyclic tensile loading at room temperature in a servo-hydraulic test stand. The maximum strain level during cycling was approximately 4000 microstrain and the stress ratio was $\mathrm{R}=0.01$. During cyclic loading, the damage state in the composite test panel was monitored at intervals of 10,000 or 20,000 cycles, using a long focal length microscope to image the free edge of the panel. Crack locations were mapped along a $2.5 \mathrm{~cm}$ length and crack density was calculated for the $+45^{\circ}, 90^{\circ}$, and $-45^{\circ}$ plies. The reported values are the averages obtained from examination of both edges of the specimen after each increment of tensile cycling. The crack density in the \pm 45 plies is scaled by a factor of $\sin \left(45^{\circ}\right)$ to account for the fiber angle. Tensile modulus was measured at the same intervals. Modulus was calculated using strain from bonded strain gages or a clip-on extensometer along with load as measured by the test machine load cell.

The permeation measurement system developed for this research consists of three basic components. The first component, the supply system, is composed of a low-pressure hydrogen gas generator, a delivery manifold, and a sealed supply attachment to the test specimen. Hydrogen gas can be supplied to either of two locations: a circular region on the specimen front face or along both of the specimen edges. The second component in the permeation system, the control volume, is connected to the back face of the specimen via a second sealed attachment and is operated at very low pressure. Both pressure and temperature in the control volume are monitored continuously. The third component, the gas analyzer, is a mass spectrometer that measures the chemical composition of the gas in the control volume. Using the pressure and temperature data from the control volume and the chemical composition data provided by the mass spectrometer, ideal gas law relations can be used to calculate the leak rate of hydrogen through the specimen. A detailed description of the hardware and the data analysis method were reported previously and can be found in Ref. [11]. The general arrangement of components within the permeability testing system is shown in Fig. 1.

In this study, hydrogen gas was supplied only to the specimen edges. The measured permeation or leak is due to combined in-plane flow through $90^{\circ}$ cracks (and to a lesser degree through the $-45^{\circ}$ cracks) and through-thickness flow through cracks in the $+45^{\circ}$ ply on the surface. Figure 2 illustrates the hydrogen gas supply and the vacuum attachment arrangement for this study.

After cycling for a specified interval, leak rate was measured at six levels of static mechanical strain and at two temperatures, $23^{\circ} \mathrm{C}$ and $-191^{\circ} \mathrm{C}$, for each of the six strain levels. During cryogenic testing, the specimen was 
lowered from room temperature to $-191^{\circ} \mathrm{C}$ by routing liquid nitrogen through an insulated enclosure on the front face of the specimen. The back face with the vacuum attachment was insulated with rigid polystyrene foam and fibrous insulation batts. Full sets of leak rate measurements were obtained after completing 170,000 and 430,000 cycles. Test intervals were chosen based on observed marked increased in crack density in the $+45^{\circ}$ and $90^{\circ}$ plies.

\section{Results}

\section{A. Damage Progression During Mechanical Cycling}

Under cyclic tensile loading, tensile longitudinal modulus decreased from approximately $55 \mathrm{GPa}$ at the start of cycling to $50 \mathrm{GPa}$ after 430,000 cycles. The modulus decrease was approximately linearly related to the number of cycles, as illustrated in Fig. 3. Microcrack density as a function of number of cycles is presented in Fig. 4. In general, edge crack density continuously increased as the number of fatigue cycles increased. The $+45^{\circ}$ plies on the specimen surface were the first to crack. Until reaching 170,000 cycles, damage progressed in an incremental fashion, exhibiting periods of crack growth followed by stable crack density. After 170,000 cycles the damage rate was observed to increase. In the $90^{\circ}$ plies edge crack growth began at approximately 100,000 cycles. Cracking in the $90^{\circ} \mathrm{C}$ plies progressed in a step-wise fashion, with a significant increase after 170,000 cycles.

\section{B. Leak Rate}

Isothermal leak rates after 170,000 and 430,000 cycles are plotted in Fig. 5 and Fig. 6, respectively for six levels of applied strain. At all levels of mechanical strain, after both 170,000 and 430,000 cycles, permeability increased significantly when the test temperature was lowered from $23^{\circ} \mathrm{C}$ to $-191{ }^{\circ} \mathrm{C}$. In order to illustrate this result further, Fig 7 shows the leak rates after 430,000 cycles as a function of test temperature. The resulting plot indicates that the drop in temperature caused leak rate to increase by factors ranging from 7 to 24 . The effect of mechanical strain on leak rate is smaller at low (cryogenic) temperatures. The effect of mechanical strain on leak rate was evaluated by normalizing leak rate at each strain level by the leak rate measured under no load at the same temperature. The curves shown on Fig. 8 indicate that permeability increased with increasing mechanical strains. The effect of mechanical strain on permeability was nearly the same at $23^{\circ} \mathrm{C}$ and at $-191^{\circ} \mathrm{C}$.

To explore how damage type affects permeability, the hydrogen leak rate was normalized by the theoretical number of crack junctions per unit area. The number of crack junctions per unit area was taken as the average crack density in the $90^{\circ}$ plies multiplied by the average crack density in the $45^{\circ}$ plies. This approach to damage characterization assumes that all cracks are sufficiently long to cross all of the cracks in the adjacent ply, thereby forming a junction. Figures $9-10$ show the results of the normalization. At room temperature the curves for the two test conditions are nearly the same; ie. the permeability of the specimen appears to be proportional to the theoretical number of crack junctions. On cooling to $-191^{\circ} \mathrm{C}$ temperature, the normalized permeability of the specimen with the higher damage level (higher crack density and larger delaminations) is significantly higher.

It is assumed that the effect of temperature is due to the differential coefficient of thermal expansion between fiber and matrix and between adjacent laminate plies of different orientation. At cryogenic test temperatures, the resulting thermal strains can open delaminations at the ply interface between the $90^{\circ}$ and the $45^{\circ}$ plies. The delaminations create multiple gas flow paths to the surface. Because there were fewer and smaller delaminations at 170,000 cycles, gas flow through the laminate in that damage state may have been much more restricted by the number of available crack junctions.

\section{Discussion}

To investigate repeatability, multiple leak tests were performed at $-191^{\circ} \mathrm{C}$ after 430,000 cycles. Results demonstrated some differences from test to test in leak rate as a function of mechanical strain. The leak rate data from these separate tests, with the exception of several data points which were obviously outliers, are shown in Fig. 9. Comparing data sets, differences of leak rate on the order of nearly one order of magnitude are apparent. The line provided in Fig. 9 indicates the average leak rate at each strain level and is shown to indicate the general trend of the mean value of leak rate. In general, measurement of leak rate at room temperature provided more consistent results than the measurements at cryogenic temperature.

It is assumed that the difficulties with measurement at cryogenic temperature are attributable to thermal shrinkage of seals within the measurement system. For example, air leakage through the vacuum attachment seal can cause large variations in the partial pressure of hydrogen in the control volume. Thermal contraction within the seals 
on the hydrogen gas supply tubes can allow hydrogen gas to leak from the supply system, permit air to enter the hydrogen supply system, or allow liquid nitrogen, which leaks from the insulated box, to enter the supply system and displace hydrogen.

Attempts were made to distinguish air leaks at the vacuum attachment from nitrogen leaks into the supply system by analyzing the variation in $\mathrm{O}_{2} / \mathrm{N}_{2}$ ratio during the experiments represented by the data points in Fig. 9 . A stable $\mathrm{O}_{2} / \mathrm{N}_{2}$ ratio would indicate air leakage, while a sudden decrease in $\mathrm{O}_{2} / \mathrm{N}_{2}$ would indicate leakage of $\mathrm{LN}_{2}$ into the supply system. Unfortunately, $\mathrm{O}_{2} / \mathrm{N}_{2}$ varied significantly in all the experiments, even those which showed little scatter in the permeability data, and no clear trends were evident. One possible reason is that the boiling point of $\mathrm{O}_{2}$ is $-183^{\circ} \mathrm{C}$, high enough that some oxygen may condense out of the air as it passes through microcracks in the specimen. At present the cause of the inconsistency in permeability measured at cryogenic temperature has not been positively identified.

\section{Concluding Remarks}

An experimental investigation was performed to develop the empirical relationships between damage state in a laminated composite and hydrogen gas leak rate through the composite. Damage was induced through room temperature cyclic loading. Hydrogen gas was supplied along the free edges of the specimen. Leak tests were then performed for a given damage state at room and cryogenic temperatures at incrementally increasing levels of static load.

Tensile modulus decreased, and microcrack damage increased, as the number of cycles increased. Crack density, as a function of ply orientation, was measured and found to correlate with the leak of hydrogen gas through the specimen. The application of static load at room and cryogenic temperatures, allowed the leak rate to be correlated against both test temperature and mechanical strain levels. The leak rate increased with increasing load level and was greater at cryogenic temperatures, regardless of mechanical strain level. Clearly, both increased mechanical strain and decreased temperature contribute to opening of the crack junctions and subsequently to the increase in leak rate.

The proposed test method, apparatus, and data reduction techniques have been found suitable for experimentally determining the leak rate of hydrogen gas in a damaged composite laminate. This technique should be applicable to a range of loading conditions and test temperatures. Primary challenges in developing the experimental method are related to preventing seal leakage in the measurement apparatus at cryogenic temperatures.

\section{References}

1. Robinson, M.J. Composite Cryogenic Propellant Tank Development. in 35th Structures, Structural Dynamics, and Materials Conference, AIAA-94-1375-CP, 1994, Hilton Head, South Carolina.

2. Bechel, V.T., et al., Effect of Stacking Sequence on Micro-Cracking in a Cryogenically Cycled Carbon/Bismaleimide Composite. Composites Part A: Applied Science and Manufacturing, 2003. 34(7): p. 663-672.

${ }^{3 .}$ Gates, T.S., et al. Thermal/Mechanical Durability of Polymer Matrix Composites in Cryogenic Environments. 44th Annual AIAA/ASME/ASCE/AHS/ASC Structures, Structural Dynamics, and Materials Conference.AIAA2003-7408, 2003. Norfolk, Virginia.

${ }^{4 .}$ Roy, S., A. Utturkar, and M. Benjamin. Modeling of Permeability and Damage in Graphite/Epoxy Laminates at Cryogenic Temperatures. 45th AIAA/ASME/ASCE/AHS/ASC Structures, Structural Dynamics \& Materials Conference, AIAA Paper 2004-1860, 2004, Palm Springs, California.

${ }^{5 .}$ Noh, J., et al. Prediction of Leakage Rate Through Damage Network in Cryogenic Composite Laminates, 45th AIAA/ASME/ASCE/AHS/ASC Structures, Structural Dynamics \& Materials Conference, AIAA Paper 2004-1861, 2004, Palm Springs, California.

6. Yokozeki, T., T. Aoki, and T. Ishikawa, Gas Permeability of Microcracked Laminates Under Cryogenic Conditions, 44th AIAA/ASME/ASCE/AHS Structures, Structural Dynamics, and Materials Conference, AIAA2003-1604, 2003, Norfolk, Virginia.

7. Rivers, H.K., J.G. Sikora, and S.N. Sankaran, Detection of Hydrogen Leakage in a Composite Sandwich Structure at Cryogenic Temperature, Journal of Spacecraft and Rockets, 2002, 39(3): p. 452-459.

${ }^{8}$. Lagoudas, D., et al. Numerical Modeling of Cryogen Leakage Through Composite Laminates, 45th AIAA/ASME/ASCE/AHS/ASC Structures, Structural Dynamics \& Materials Conference, AIAA Paper 2004-1862, 2004, Palm Springs, California.

9. Whitley, K. S., T. S. Gates "Thermal/Mechanical Response of a Polymer Matrix Composite at Cryogenic Temperatures," AIAA Journal, Vol. 42, no. 10, October 2004, pp. 1991-2001. 
10. Grenoble, R.W., T. S. Gates, K.S. Whitley, "Permeability and Life-time Performance of Composite Materials for Cryogenic Fuel Tanks," 2003 International Mechanical Engineering Congress and Exposition, Washington, D.C., November 15-21, 2003.

11. T. Gates, R. Grenoble and K. Whitley, Permeability and Life-time Durability of Polymer Matrix Composites for Cryogenic Fuel Tanks. 45th AIAA/ASME/ASCE/AHS/ASC Structures, Structural Dynamics and Materials Conference, AIAA-2004-1859, Palm Springs, California.

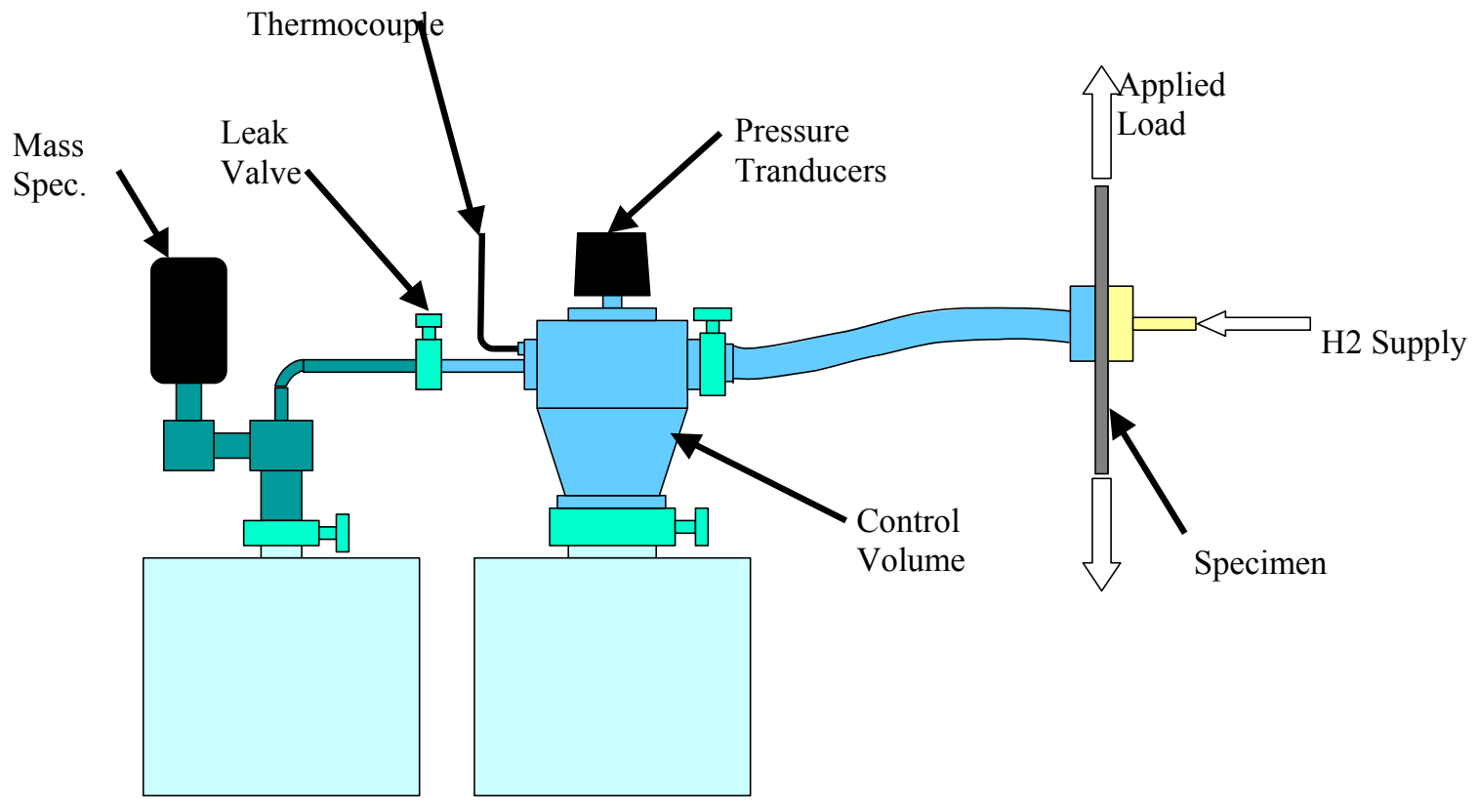

Figure 1. Conceptual arrangement of components in permeability measurement system. 


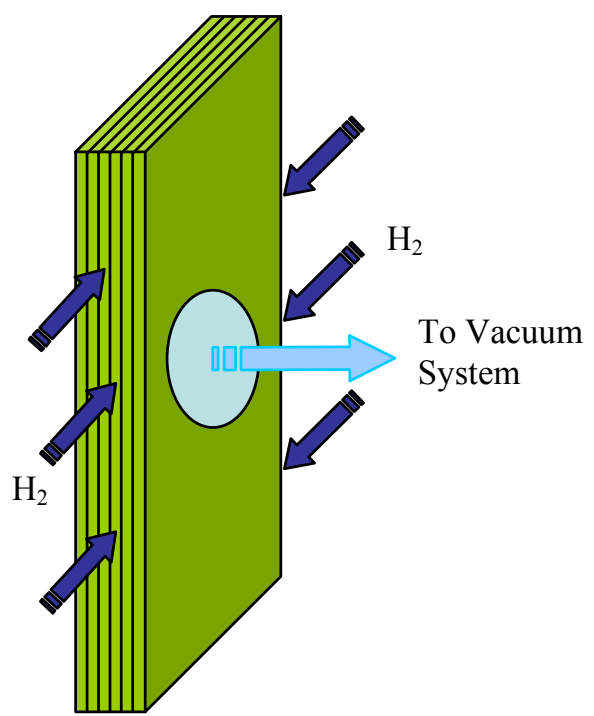

Figure 2. Gas delivery to specimen edge with vacuum attachment in center.

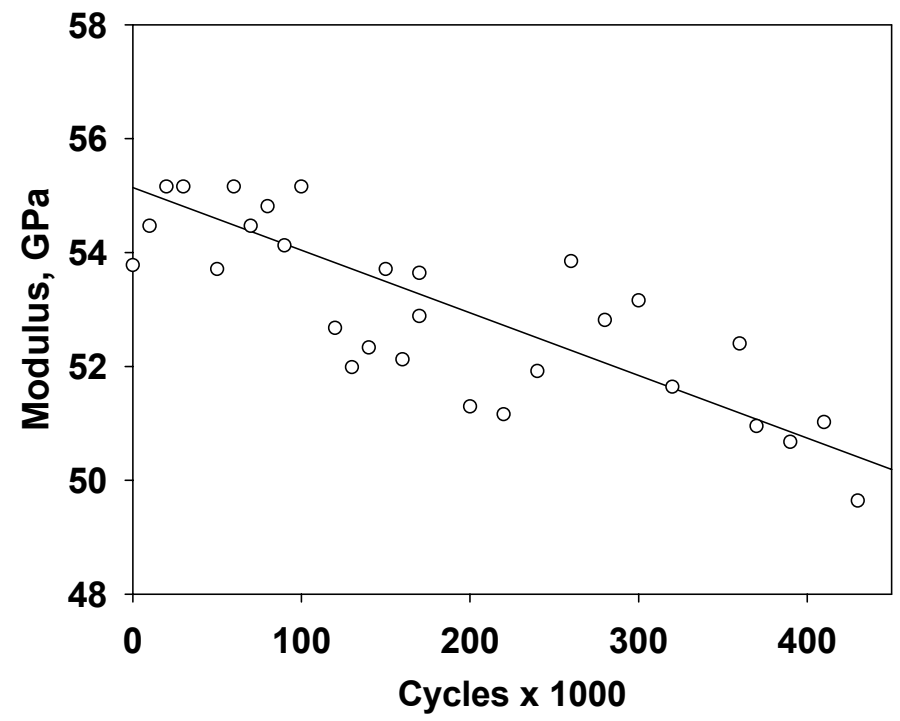

Figure 3. Tensile modulus reduction due to cycling.

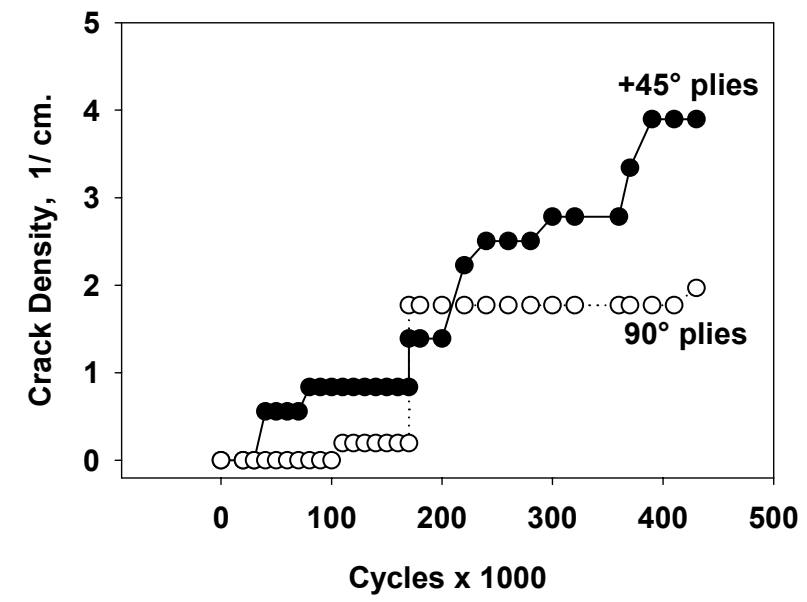

Figure 4. Average crack density as a function of number of tensile cycles.

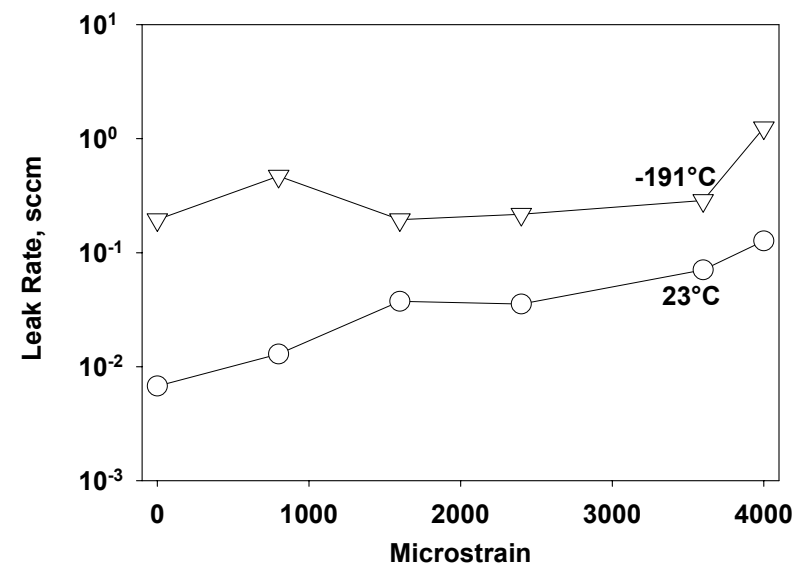

Figure 5. Leak Rate at $23^{\circ} \mathrm{C}$ and $-191^{\circ} \mathrm{C}$, tested after 170,000 cycles. 


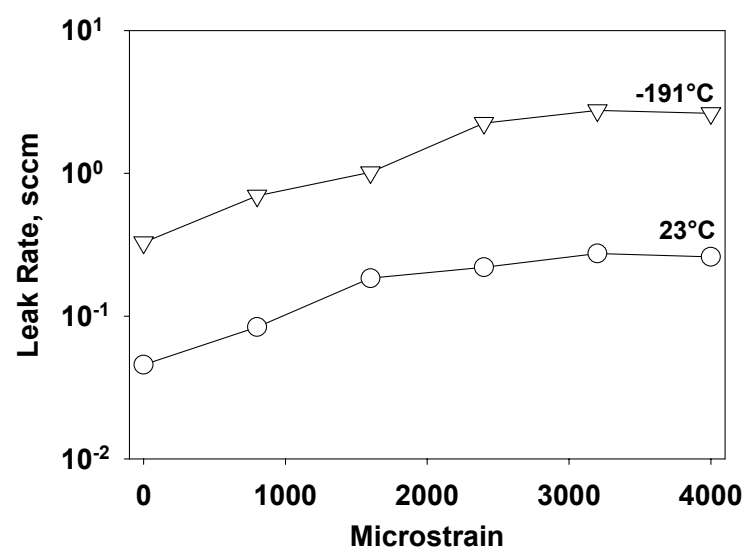

Figure 6. Leak Rate at $23^{\circ} \mathrm{C}$ and $-191^{\circ} \mathrm{C}$, tested after $430 \mathrm{k}$ cycles.

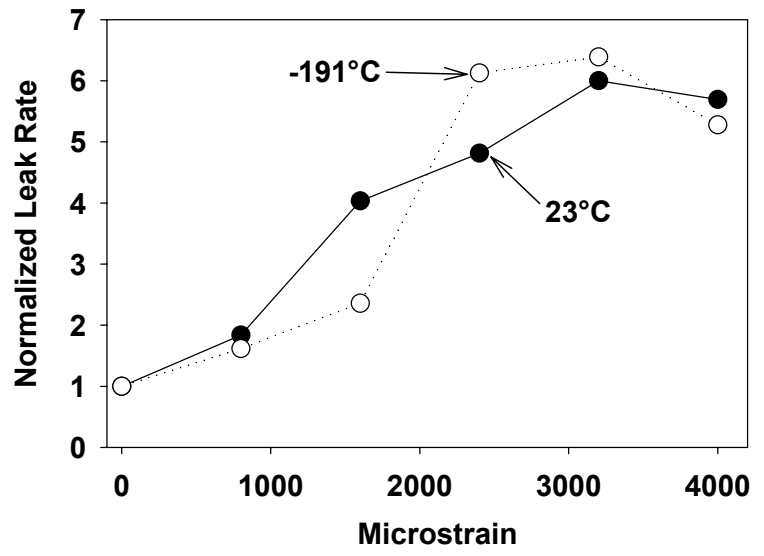

Figure 8. Change in leak rate due to increasing mechanical strain, tested after 430,000 cycles.

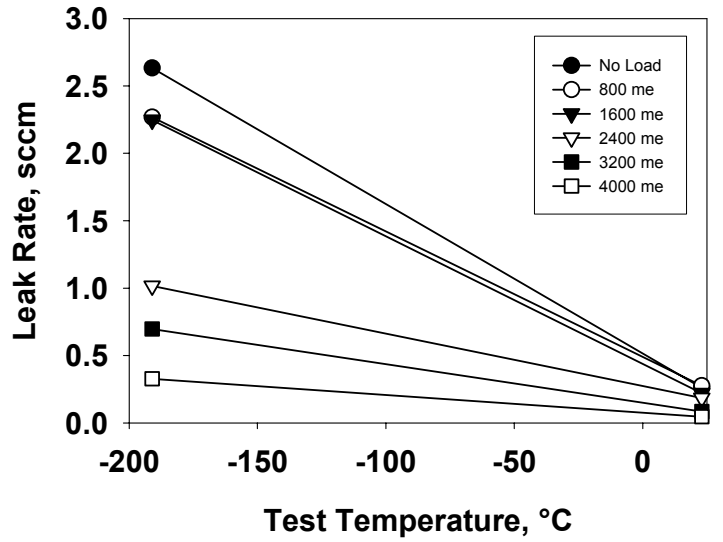

Figure 7. Leak rate under several levels of mechanical strains after 430,000 cycles.

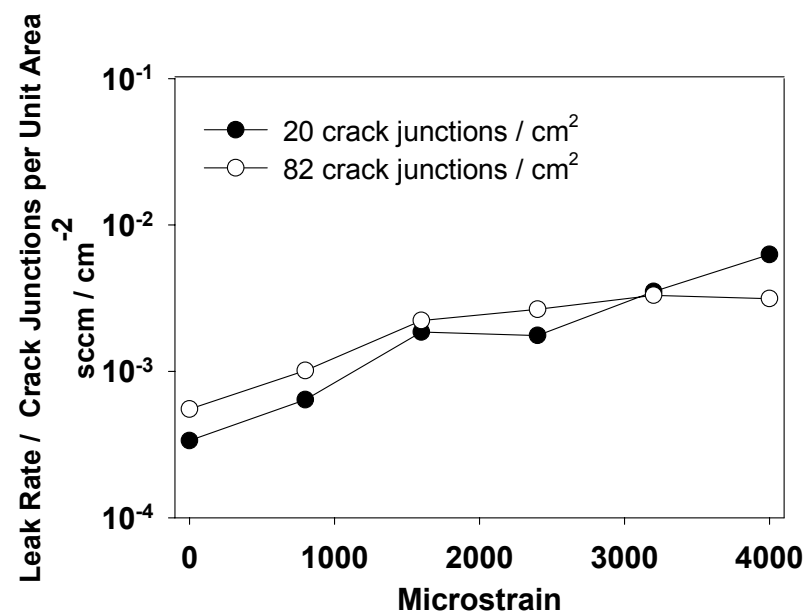

Figure 9. Leak Rate at $23^{\circ} \mathrm{C}$ Divided by the Theoretical Number of Crack Junctions. 


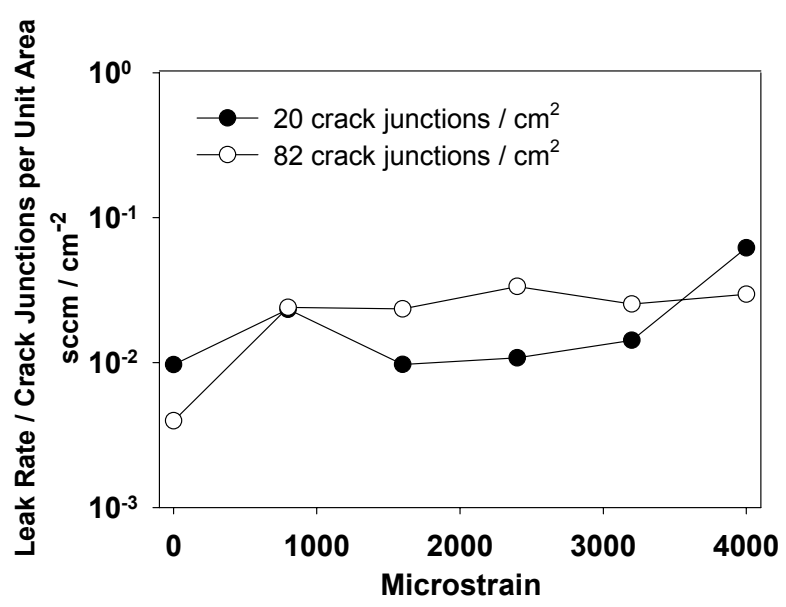

Figure 10. Leak Rate at $-191^{\circ} \mathrm{C}$ Divided by the Theoretical Number of Crack Junctions

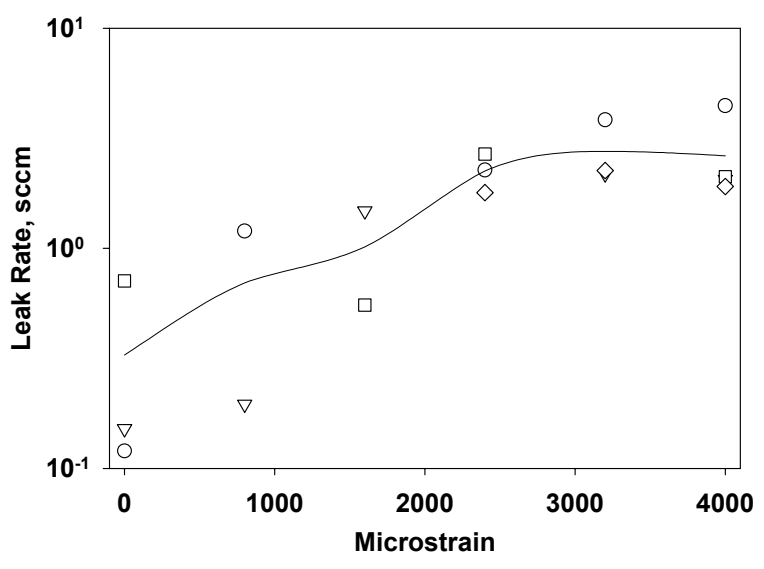

Figure 11. Repeatability of Leak Rate Measurements at Cryogenic Temperature 